\title{
ERRATUM
}

Mark Voorneveld • Willemien Kets

Henk Norde

\section{An axiomatization of minimal curb sets}

Published online: 5 April 2006

(C) Springer-Verlag 2006

\section{Int J Game Theory (2005) 33:479-490}

On page 485 , the proof of step 4 should read as follows:

Step 4: $\varphi(G) \in \min -\operatorname{curb}(G)$.

Let $X \in \varphi(G)$. By Step $1, X \in \operatorname{curb}(G)$. Suppose $X \notin \min$-curb $(G)$ : there is a $Y \in \min$-curb $(G)$ with $Y \subset X$. By Step 3, there is a $Z \in \varphi(G)$ with $Z \subseteq Y$. But since $Z \subseteq Y \subset X$ and $X, Z \in \varphi(G)$, we have a contradiction with the assumption that $\varphi$ is nonnested. Conclude that $X \in \min$-curb $(G)$.

The online version of the original article can be found at http://dx.doi.org/10.1007/s00182-0050208-6

M. Voorneveld $\cdot$ W. Kets $\cdot$ H. Norde

Department of Econometrics and Operations Research,

Tilburg University,

The Netherlands

M. Voorneveld ( $\varangle)$

Department of Economics,

Stockholm School of Economics,

Sweden

E-mail: Mark.Voorneveld@hhs.se 